\title{
Experts call for radical re-allocation of NHS dental funds
}

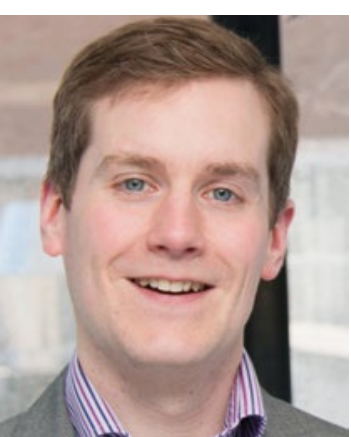

Dr Chris Vernazza

Experts have suggested that NHS England stop funding routine scaling and polishing of teeth and some orthodontic treatments so the dental budget is spent more appropriately on what will be more beneficial to patients.

A research team at Newcastle University's School of Dental Sciences has recommended that NHS England should save $£ 319$ million by cutting three dental treatments in order to fund services which will improve access to dental care as well as oral health promotion.

The treatments they want to be cut are the routine scale and polish and orthodontics for young people with mild malocclusions as well as adult orthodontics.

The RAINDROP project (Resource allocation in NHS dentistry: recognition of societal preferences) began in 2016, led by $\mathrm{Dr}$ Chris Vernazza, Clinical Senior Lecturer in the School of Dental Sciences.

The research team included economists as well as dentists and their work (https:// research.ncl.ac.uk/raindrop/) was funded by the National Institute for Health Research (NIHR).
Currently, NHS dental budgets are set regionally, but the funding arrangements often maintain historic allocations, partly due to lack of resources to review current allocations.

The strategy of the Newcastle research team was to apply economic principles to NHS priority setting and incorporate the views of the public and patients.

A panel of ten people were selected and made recommendations according to various criteria which included evaluation of current services and views of the public.

The panel comprised patient representatives, dental network chairs, dental lead commissioners, dental public health consultants and an academic, to assess current funding models and services.

The research team presented their findings on 2 April 2019 at a policy briefing in London and concluded that after disinvesting in some treatments - orthodontics and the scale and polish in order to save $£ 319$ m - money should be invested in services which would deliver access to general dental services.

Their recommendations included:

- Developing access at NHS practices ( $£ 135$ million)

- Local authority oral health promotion contracts ( $£ 5$ million)

- Online NHS 111 link so patients can book appointments directly with practices

- Dental treatment in care homes ( $£ 13$ million).

Ironically, given that oral disease prevention was a priority, the panel decided not to invest in preventative sessions.
The model developed by the panel allowed an additional ten minutes for every NHS dental patient to receive oral health advice but this was considered too costly.

The trade-off, said the researchers, would be a reduction in the amount of orthodontics the NHS provides - by not treating those with moderate need and not providing adult orthodontics - and stopping routine scaling and polishing of teeth.

Dr Vernazza said: 'Public money used for NHS dentistry is not being spent in the most effective way to ensure that patients are given the best care possible.

'Major changes, such as those we have recommended, are often difficult to implement at a national level. It may be that any changes need to be made as part of ongoing and emerging processes, such as dental contract reform which is currently scheduled for roll out next year.'

Peter McCallum, Director of External Relations at the British Orthodontic Society, said: 'It is important that we consider the social, emotional and functional handicaps that produce a significant need for orthodontic treatment in addition to purely dental health benefits.'

BDA Chair Mick Armstrong said: 'This is an interesting piece of academic research. Patients should have a voice in shaping health policy. But its practical applications will be limited by an inflexible dental contract and the simple fact of priorities that have already been set for the next decade at Westminster.'

\section{Full portfolio of $B D J$ titles go online}

Two of the BDJ's sister titles BDJ In Practice and BDJ Student are going online, meaning that all six $B D J$ titles in the portfolio are now accessible on the web, allowing readers access to a broad range of titles covering all aspects of the world of dentistry.

The full portfolio includes BDJ, BDJ In Practice, BDJ Team, Evidence-Based Dentistry, BDJ Open and BDJ Student.
Any BDA members who want to visit these journals online should visit https://bda.org/, $\log$ in and then click on the $B D J$ tab, which will take them to a new page offering a link to all the $B D J$ titles.

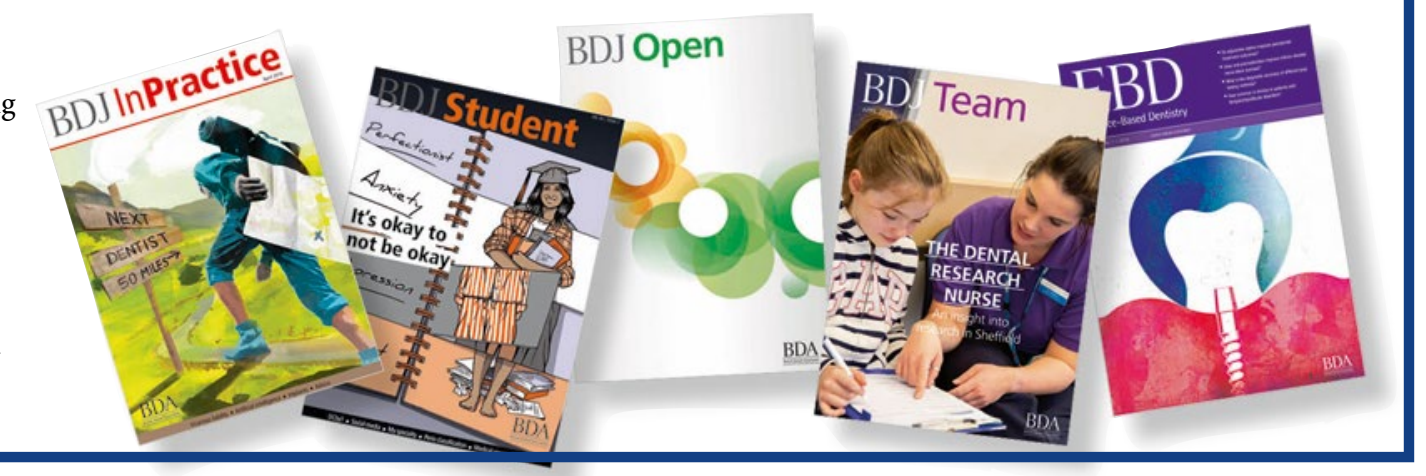

